\title{
Reliability/Quality, Performance/Design, Innovativeness: Their Different Roles in Generating Buzz for Automobile
}

\author{
Jie Feng \\ SUNY Oneonta
}

This empirical research explains the relationship between products attributes of an automobile and its volume of word of mouth and the mechanism of stimulating positive word of mouth and minimizing negative word of mouth? The primary findings are as follows: (1) failing reliability/quality of an automobile stimulates negative word of mouth whereas failing its performance/design does not necessarily lead to negative word of mouth. (2) Improving performance/design of a car produces positive word of mouth whereas improving its reliability/quality does not necessarily translate to positive word of mouth. (3) A new (re) designed model drives more both positive and negative word of mouth than a nonnew one. Similarly, a car model with a short history drives more both positive and negative word of mouth than a model with a long history.

Keywords: Word of Mouth, Consumer Review, Buzz Marketing

\section{INTRODUCTION}

Traditionally, a notion about word of mouth is that it is a powerful force yet beyond direct control of marketer (Westbrook 1987). Early works of word of mouth argue that word of mouth may have the most influence among all the sources of information that consumers turn to before making a purchase decision (i.e. Katz and Lazarsfeld 1955; Day 1971). Recently, Chevalier and Mayzlin (2006) and Liu (2006) utilize online consumer reviews to show word of mouth's impact on sales. Despite its power, Word of mouth is implicitly assumed a force out of directly controlling by firms due to the fact that it is the consumer who generates word of mouth. However, a stream of recent studies are beginning to find out the determinants of word of mouth and attempting to give managerial implications that how to successfully manage word of mouth (i.e. Dellarocas 2003; Godes and Mayzlin 2004; Godes, et al 2005; Dellarocas 2006; Mayzlin 2006).

One premise of such successful word of mouth management is to understand a potential relationship between product and word of mouth. This is a fundamental knowledge in the sense that a large percentage of word of mouth's subjects are only about product itself (Keller 2007). If the product A is able to naturally generate more word of mouth than the product B given a product category, it is essential to know that what attribute dimensions of a product make A more powerful than B and how does that happen? In the context of automobile, there are different attribute dimensions of a car, such as reliability/quality, performance/design, new-designed versus non new-designed, model with a long history versus model with a short history, body style (i.e. SUV, Pickup, etc), price and so on. Suppose the model A is a new-designed convertible car with excellent performance and average quality and the model 
$\mathrm{B}$ is a non new-designed small car with an average performance but excellent quality. Are buyers who buy the model A more (less) likely to spread WOM about the model A than buyers who buy the model B about the Model B? More interestingly, are buyers who buy the model A more (less) likely to spread positive (negative) WOM about the model A than buyers who buy the model B about the Model B? From a substantive standpoint, the second question has its important implication: in order to maximize positive WOM (minimize negative WOM), should an auto manufacturer put a limited source to improve reliability/quality or to improve performance/design?

The context of our investigation is word of mouth for automobiles. We choose automobiles for a number of reasons. First, it is a category that has been studied previously (e.g. Pauwels et al. 2004; Srinivasan et al. 2008; Bucklin, Siddarth and Silva-Risso 2007). Second, word of mouth behavior is likely to occur since this is a category that consumers would like to research and discuss. Third, the three product attributes that we examine, reliability/quality, performance/design and innovativeness, play critical roles in the auto industry. Automobile manufacturers can get insights from this study how to design their models in order to maximize positive word of mouth effect or minimize negative word of mouth effect. Finally, we choose automobiles for its economic importance because the automobile business represents more than 3\% gross domestic product (Srinivasan et al. 2008).

We build our theory framework on the seminal works of postpurchase emotions (Westbrook 1987; Westbrook and Oliver 1991; Oliver, Rust and Varki 1997; Rust and Oliver 2000); regulatory focus theory (Higgins 1997), and recent works of goal-attribute compatibility (Chernev 2004); utilitarian and hedonic design benefits (Chitturi, Raghunathan and Mahajan 2007, 2008); surprise effect on WOM (Derbaix and Vanhamme 2003). Our theory framework is going to answer a series of questions: what attributes of a product, how and why these attributes are related to word of mouth behavior?

\section{THEORY}

Consistent with previous research, our basic theory framework is that product attributes influence postpurchase behavior through postpurchase emotions or simply the attributes-emotions-behaviors model (Westbrook 1987; Oliver, Rust and Varki 1997; Rust and Oliver 2000; Chernev 2004; Chitturi, Raghunathan and Mahajan 2008). Recent studies find out that emotions that are in high arousal level (positive emotions such as delight; negative emotions such as anger; neutral emotion such as surprise) lead to a greater amount of word of mouth than emotions that are in low arousal level (positive emotions such as satisfaction; negative emotions such as dissatisfaction, Chitturi, Raghunathan and Mahajan 2008; Derbaix and Vanhamme 2003). On the other hand, product attributes (i.e. reliability/quality and performance/design) are found to be associated with different emotions that are either in high or low arousal level (Chernev 2004). Combining these two mechanisms (see figure 1), we posit that three critical product attributes - reliability/quality, performance/design and innovativeness, are related to word of mouth behavior. In the case of an automobile, reliability/quality refers to how reliable an automobile is. Performance/design refers to how well an automobile performs a task or how stylish the body of an automobile is. There is an important distinction between these two attributes. Improving reliability/quality evokes positive emotions that are low in arousal whereas improving performance/design evokes positive emotions that are high in arousal. In contrast, failing reliability/quality evokes negative emotions that are in high arousal whereas failing performance/design evokes negative emotions that are low in arousal. Since emotions that are high in arousal lead to a greater word of mouth than emotions that are low in arousal (Chitturi, Raghunathan and Mahajan 2008). We, therefore, predict that improving performance/design leads to greater positive word of mouth than improving reliability/quality. However, failing reliability/quality leads to greater negative word of mouth than failing performance/design. The third attribute we consider is innovativeness, which refers to the newness and the product life cycle stage in our study. We reason that an innovative product is more likely to evoke surprise than a non innovative product (Derbaix and Vanhamme 2003), and since surprise is a neutral emotion that are in high arousal (Westbrook 1987; Westbrook and Oliver 1991; Oliver, Rust and Varki 1997; Rust and Oliver 2000), we predict that an innovative product leads to greater word of mouth than a non-innovative product. 
FIGURE 1

THEORY FRAMEWORK

$\begin{array}{lll}\text { Attributes } & \text { Emotions } & \text { Behaviors }\end{array}$
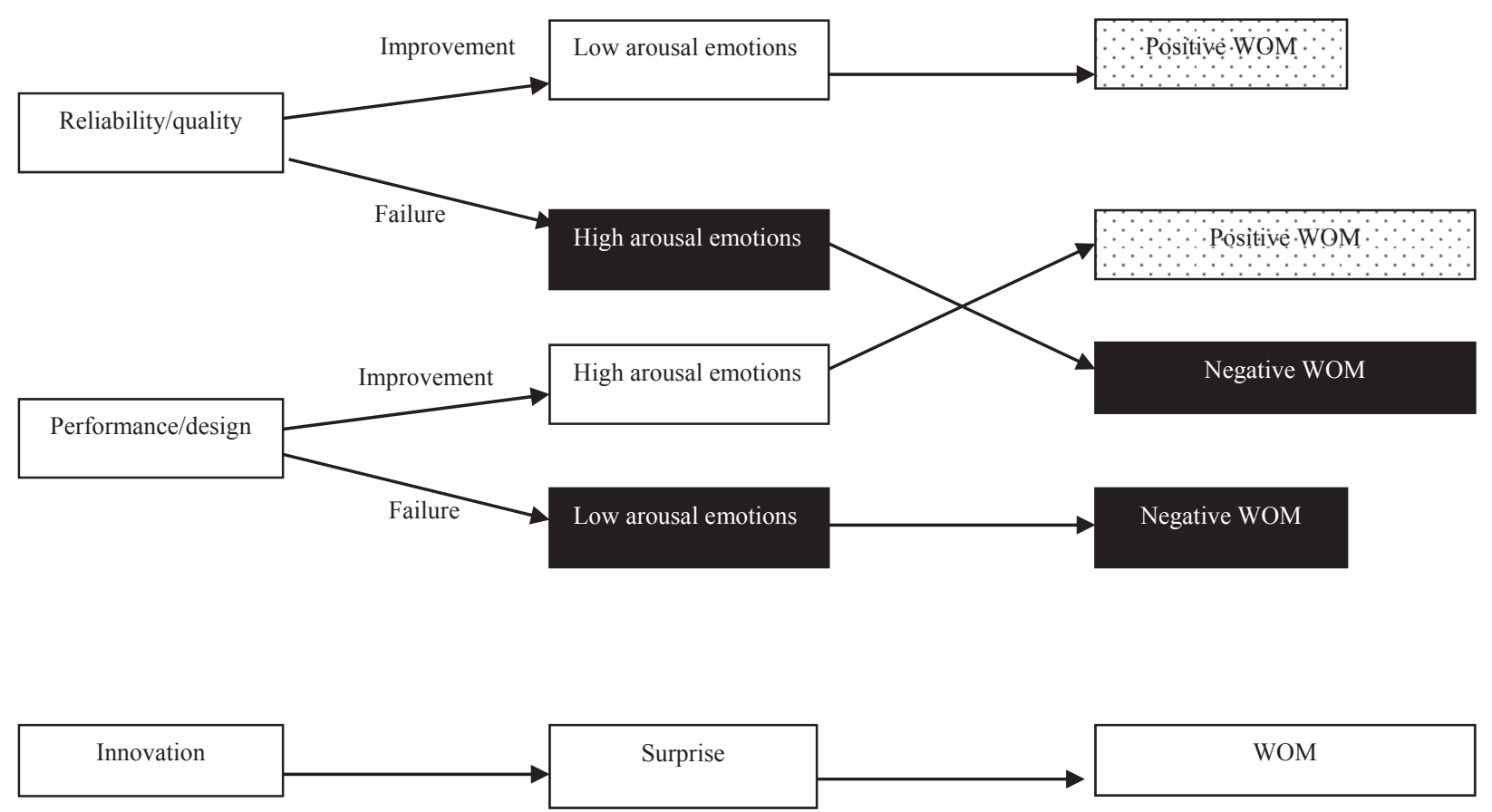

\section{Reliability/Quality, Performance/Design and Word of Mouth}

It is argued that consumers' behaviors (i.e. choice of a product) are associated with their goals (Chernev 2004; Chitturi, Raghunathan and Mahajan 2008). According to regulatory focus theory (Higgins 1997), prevention goals have "must meet" characteristic, such as "behaving in a safe and secure manner" or "being responsible", aiming at minimizing negative outcomes or reducing the probability of a painful experience. In contrast, promotion goals have "aspire to meet" characteristic, such as "looking cool" or being sophisticated", aiming at maximizing positive outcomes or increasing the probability of a pleasant experience. Chernev (2004) and Chitturi, Raghunathan and Mahajan (2007, 2008) suggest that prevention goals can be fulfilled by utilitarian attributes whereas promotion goals can be fulfilled by hedonic attributes. Similarly, Chernev (2004) suggests that reliability/quality attributes are more likely to be associated with security, safety, and the minimum of negative outcomes, therefore fit prevention goals. Conversely, performance/design attributes are more likely to be associated with accomplishment, achievement and maximum of positive outcomes, therefore fit promotion goals.

Building on prior research, we reason that since reliability/quality has a "must meet" or necessitiesneed characteristic and the failure of this attribute may cause the loss of the basic function. For example, serious mechanic problems with engine, transmission or drive system could cause an automobile a complete breakdown and lost its basic function. We expect the failure of reliability/ quality of a product evokes the owner's intensive negative emotions, such as anger (Chitturi, Raghunathan and Mahajan 2008), which is an emotion that is in high arousal. Moreover, the negative emotions are more likely to be toward the manufacture because consumers may simply believe this failure of reliability/quality is due to the manufacturer rather than their own choice (Westbrook 1987; Chitturi, Raghunathan and Mahajan 2008). In contrast, performance/design has a "aspire to meet" or luxuries-want characteristic and the failure of this attribute is unlikely to influence a product's basic function, thus, we expect this failure 
evokes less intensive emotions, such as minor dissatisfaction (Chitturi, Raghunathan and Mahajan 2008), which is an emotion that is low in arousal. For example, driving an out-of-date style car could be an unpleasant experience or leads to dissatisfaction at most, but it is unlikely to cause anger. Furthermore, the negative emotions are less likely to be toward the manufacture because consumers may blame their bad tastes or choices (Westbrook 1987; Chitturi, Raghunathan and Mahajan 2008). On the other hand, improving performance/design is toward the promotion goal as the maximum of the positive presence, and the enhancement of pleasure. Therefore, we expect improving performance/design evokes positive emotions, such as cheerfulness, excitement or delight (Chitturi, Raghunathan and Mahajan 2008), which are high in arousal. For example, consumers may be delighted when car designers add luxury interior, GPS or video equipment to the car model. Conversely, improving reliability/quality is unlikely to help too much if the prevention goal as the minimum of negative presence has been achieved. Therefore, we expect improving reliability/design evokes positive emotions, such as confidence, security or peace in mind (Chitturi, Raghunathan and Mahajan 2008), which are low in arousal.

It is argued that different emotions are associated with different behavior tendency (Lazarus 1991). The likelihood of making an action is dependent on the level of arousal, such that an emotion that is high in arousal leads to a high probability of making an action whereas an emotion that is low in arousal leads to a low probability of making the same action (Mehrabian and Russell 1974; Roseman 1991). Chitturi, Raghunathan and Mahajan (2008) report that consumers are more likely to engage in negative word of mouth behavior when their utilitarian experiences have not been met than their hedonic experiences have not been met. Conversely, consumers are more likely to engage in positive word of mouth behavior when their hedonic experiences have been exceeded than their utilitarian experiences have been exceeded. Following this logic, we, therefore, predict that failing reliability/quality attributes evokes negative emotions that are high in arousal, leads to a greater negative word of mouth than failing performance/design attributes when negative emotions that are low in arousal have been resulted from. In contrast, improving performance/design attributes evokes positive emotions that are high in arousal, leads to a greater positive word of mouth than improving reliability/quality attributes when positive emotions that are low in arousal have been resulted from. Therefore, we hypothesize the following:

H1: Failing reliability/quality has a larger effect on negative word of mouth tendency than failing performance/design.

H2: Improving performance/design has a larger effect on positive word of mouth tendency than improving reliability/quality.

\section{Innovativeness and Word of Mouth}

It is the notion that new product is the engine of growth (Cohen, Eliashberg and Ho 1997). A number of studies show that automobile manufactures heavily reply on innovation to improve sales (Hoffer and Reilly 1984; Sherman and Hoffer 1971), financial performance (Srinivasan et al. 2008) and firm value (Pauwels et al. 2004). Although it is implicitly assumed that the diffusion of new product involves word of mouth, to our knowledge, there is no empirical evidence showing innovation increase word of mouth. We again apply the basic model "attributes-emotions-behaviors" and show that the notion of more word of mouth due to innovation is theoretically correct.

The innovativeness of a specific product (i.e. a car model) can be classified based on two dimensions: the newness and the product life cycle stage. The newness refers to three relatively new conditions: 1) the product is new to the market (i.e. 2001 Toyota Prius Hybrid is the first Hybrid model in the market); 2) the product is new to the company (i.e. 2003 Porsche Cayenne is the first SUV developed by Porsche); 3) the product is re-designed or updated version of the existing product (i.e. 2004 Toyota Prius is the updated version of Toyota Prius, which has been existed in the market since 2001). The life cycle stage refers to how many years the specific product has been in the market. For example, by the time the 2006 Infiniti $\mathrm{G}$ was launched, it has been in the market for 16 years. Thus, the newness dimension can capture immediate or short-term innovative effect whereas the life cycle stage dimension can capture long-term 
innovative effect. We argue that these two attributes dimensions are associated with word of mouth behavior through an emotion called surprise.

Surprise is neutral emotions elicited by a schema discrepancy (Derbaix and Vanhamme 2003). In the marketing context, consumers may have a feeling of surprise when they experience unexpected product/service/attributes (Derbaix and Vanhamme 2003). We reason that the newer product is more likely to surprise consumers because consumers may never experience the product/attributes before; or consumers' private perceptions about the nature of the product do not match the inputs. An example of the former situation would be consumers experience many new functions and features of Toyota Prius Hybrid model that no other existing models can offer. It is expected that consumers are more likely to be highly involved with the product, producing "a tension...not eased by the use of the product alone but must be channeled by way of talk....to provide relief" (Dichter 1966, p148). An example of latter situation would be a former customer of Porsche experience 2003 Porsche Cayenne SUV and has to update her previous perception of Porsche and feel surprised by the model. With regard to the product life cycle stage, following the same logic, we expect that the longer the product has been existed in the market, the less likely that product surprises consumers.

Since surprise itself is an emotion that is high in arousal (Westbrook 1987; Westbrook and Oliver 1991), and also surprise is an amplifier of either positive or negative emotions (Westbrook 1987), the likelihood of making certain post consumption behavior is expected to be higher for surprising consumers than non surprising consumers. A recent experiment by Derbaix and Vanhamme (2003) confirms this expectation and they find that surprising consumers are more likely to indulge word of mouth behavior, measured by the frequency and amount, than non surprising consumers. We, therefore, reason that a newer product is more likely to surprise consumers, and thus leads to more word of mouth behavior. Furthermore, due to an amplifier effect of surprise, a newer product may lead to more both negative word of mouth and positive word of mouth. Similarly, the longer the product has been existed in the market, the less likely that product surprises consumers, and leads to less total word of mouth behavior, less negative word of mouth as well as less positive word of mouth.

H3: The newness is positively associated with negative and positive word of mouth tendency.

H4: The product life cycle stage is negatively associated with negative and positive word of mouth tendency.

\section{DATA}

Our data come from three major sources: online site of Consumer Reports magazine (www.consumerreports.org) for word of mouth data and three product attributes: reliability, innovativeness and body style; online site of J.D. Power and Associates (www.jdpower.com) for initial quality, performance/design and price; online site of Automotive News magazine (www.autonews.com) for sales data.

\section{Data from Consumer Reports \\ Word of Mouth Data}

We chose Consumer Reports as the source of word of mouth data for two important reasons: first, it is used by many consumers for information on cars, and Ratchford, Lee and Talukdar (2003) find that $6.59 \%$ of online automobile information searchers use the online site of Consumer Reports, which is the second largest car information website searchers turn to; second, the online site of Consumer Reports only permits its' paid members to post reviews of cars. This type of system minimizes the probability that auto manufactures anonymously post online reviews praising its own models or bad word of mouth about competitors, the situation pointed out by Dellarocas (2006). The latter condition is critical because our assumption is that online word of mouth data is the proxy of word of mouth in general which is beyond direct manipulation and control of companies. 
Consumers who wish to post reviews at Consumer Reports go through the following steps. First, they pay a member fee and register to become members. Second, they choose the specific car, in terms of year, make and model, which they own and wish to review. They can then rate the car using a scale with different number of stars to represent their rating as follows: 5='love it', 4='pretty good', 3='Ok', 2='not so hot' and $1=$ 'hate it'. They can then go on to provide key points of their review such as pros and cons of the model. Finally, they can write detailed reviews such as their driving experience, comfort of the car and any overall comments and recommendations.

The online site of Consumer Reports launched the online consumer review platform in early 2004. Currently, the site allows visitors to review any make and model of car sold in the US from the year 2000 to date. We collected the number of reviews as our measure of the volume of word of mouth for 1024 model varieties (e.g. 2005 Honda Accord) from 36 brands. This measure has been applied a number of studies on word of mouth in recent year (e.g. Dellacrocas and Narayan 2006; Liu 2006). We denote this variable as TWOM in our analysis. Similarly, we collected the number of reviews rating as 5 ("love it") as the measure of the volume of positive word of mouth, and the number of reviews rating as 2 ("not so hot") or 1 ("hate it") as the measure of the volume of negative word of mouth. We believe that reviewers" rating of the car model reflect the valence of word of mouth because reviewers are unlikely to post negative reviews when they claim that "they love the product" before the reviewing process or post positive reviews when they claim that "they hate the product". We denote the volume of positive and negative word of mouth as PWOM and NWOM, respectively.

\section{Reliability}

According to Consumer Reports, Consumer Reports National Research Center conducts Annual Auto Survey based on over 1.4 million responses. Respondents report on any serious problems they have with their vehicles that they considered serious because of cost, failure, safety, or downtime, in 17 trouble spots such as engine, transmission or driving system. The individual's response of each car model then to be aggregated to get reliability/quality score ranging from 5 ("better") to 1 ("worse") for each car model (e.g. 2005 Honda Accord). We use Consumer Reports' reliability rating because it is the most comprehensive and largest reliability data, and also because Consumer Reports is a nonprofit consumer organization and provides unbiased product information. We denote this reliability score of Consumer Reports as RELI.

\section{Innovativeness}

As mentioned previously, we classify the innovativeness of a car model to two dimensions: the newness (we denote it as NEW) and the product life cycle stage (we denote as STAGE). Newness captures whether the specific model is new to the market or new to the auto manufacturer or re-designed or updated version of the existing model. For instance, since the Toyota Prius was first introduced to the US market in 2001, the variable NEW would be assigned a value of 1 for the 2001 Toyota Prius in our data. The next time this variable takes on a value of 1 when a redesigned 2004 Toyota Prius was introduced. The second variable, STAGE, measures how many years the model has been available in the US market for. Some models have a very long history. The Infiniti G, for example, was introduced in 1991 and, hence, would have a 15 year history by the time the 2005 Infiniti G was launched. Honda Pilot, on the other hand, was introduced in 2003 and would, therefore, only have a three year history by the time the 2005 Honda Pilot was introduced into the US market.

Body Style

We collected body styles data for each model based on Consumer Reports' classification. Specifically, each model is assigned to one of following eleven styles: SUV, pickup, van, sports, luxury, convertible, small, large, family, coupe and wagon. 


\section{Data from J.D. Power and Associates}

(Initial) Quality

J.D. Power and Associates conduct the Initial Quality Study (IQS) to construct a rating ranging from 5 ("among the best") to 2 called "Initial Quality" for each car model (e.g. 2006 Toyota Camry). This score looks at owner-reported problems in the first 90 days of new-vehicle ownership, this score is based on problems that have caused a complete breakdown or malfunction, or where controls or features may work as designed, but are difficult to use or understand. We use J.D.Power and Associates' Initial Quality rating and Consumer Reports' Reliability at the same time because the former reports the short term quality problem while the latter reports the long term quality problem. Moreover, several published marketing studies (e.g. Srinivasan et al. 2008; Pauwels et al. 2004) use J.D. Power's IQS data. We denote this variable as QUAL.

\section{Performance/Design}

J.D. Power and Associates conduct Automotive Performance, Execution and Layout (APEAL) study to construct a rating ranging from 5 ("among the best" )to 2 called "overall performance and design" for each car model (e.g. 2006 Toyota Camry). This score measures customer perceptions on the design, feature, layout, comfort and performance of their cars. We use J.D.Power and Associates' performance and design rating because it is the most comprehensive performance and design data, and also because several published marketing studies (e.g. Srinivasan et al. 2008; Pauwels et al. 2004) use J.D. Power and Associates auto data. We denote this variable as PERF.

\section{Price}

Finally, we collected price for each model from J.D. Power and Associates. We denote this variable as PRICE.

\section{Data from Automotive News \\ Sales}

We also collected data on the number of units of each make and model year in the US market from the Automotive News website. Thus, for instance, our model sales data would indicate that there were a total of 308,415 unit sales of the 2005 Honda Civic and 51,043 unit sales of the 2003 Audi A4 model. We denote this variable as SALES.

\section{MODEL}

In the previous section, we mentioned that our data set contains the unit sales of a specific model version (i.e. 2003 Honda Accord) and the volume of word of mouth (as measured by the number of reviews) for this model version. According to Greene (2003), our data can be treated as grouped data consisting of proportions, which is defined as the number of reviews of a specific model version divided by the unit sales of this model version. Alternatively, if we have the huge data set at the car owner level, and we observe each car owner's word of mouth behavior toward a specific model version (i.e. post a review or doesn't post a review) and car attributes (i.e. reliability/quality) that are same for each car owner who has the same model version, aggregating this data by the model version forms the data set we are investigating. Since our response variable is proportion, a Binomial response model can be applied in our study (Greene 2003; Browne 1998; Hox 2002). ${ }^{1}$

$y_{i} \mid \pi_{i} \sim$ Binomial $\left(n_{i}, \pi_{i}\right)$, where $\operatorname{logit}\left(\pi_{i}\right)=\beta^{\prime} x$

The structure of our data, however, suggests that the traditional Binomial model may not be appropriate. Our data set has a nested structure in which information is sampled at three levels: variables at the bottom level vary by model version, at the middle level by band model, and at the top level by 
brand. From statistical perspective, within one brand, Honda for example, Honda Accord and Honda Civic share many characteristics (i.e. brand image) that may influence the response. Similarly, within the same brand model, Honda Accord for example, different versions of Honda Accord share even more characteristics (i.e. body style). Appropriate for the analysis of such data is the multilevel regression model (Goldstein 1998) or HLM (Bryk and Raudenbush 1992), which accounts for the lack of independence across different cases for some variables, and thus overcomes the limitations of traditional methods of analyzing nested data. There is recent precedence in marketing for the use of HLM (e.g. Mittal, Feick and Murshed 2008; Venkatesan, Mehta and Bapna 2007). Therefore, the model (1) we specified above can be updated to the 3 levels Binomial response model with random effects which can be defined as follows:

$y_{i j k} \mid \pi_{i j k} \sim$ Binomial $\left(n_{i j k}, \pi_{i j k}\right)$, where

$\operatorname{logit}\left(\pi_{i j k}\right)=\mu+\alpha^{\prime} y_{k}+\gamma^{\prime} z_{j k}+\beta^{\prime} x_{i j k}+u_{j k}+v_{k}$

$$
u_{j k} \sim N\left(0, \sigma_{u}^{2}\right) ; v_{k} \sim N\left(0, \sigma_{v}^{2}\right)
$$

Specifically, each i model version of $\mathrm{j}$ brand model from $\mathrm{k}$ brand is viewed as a draw from a specific binomial distribution that has a known parameter $n_{i j k}=$ number of car owners for a specific model version, and an unknown parameter $\pi_{i j k}$, the proportion of car owners of a specific model version who post reviews. Logit function of $\pi_{i j k}$ links to three sets of predictor variables, $y_{k}$ vary at brand level, $z_{j k}$ vary at brand model level, and $x_{i j k}$ vary at model version level. Note that brand effect $v_{k}$ and brand model effect $u_{j k}$ are introduced to the model through the intercept $\mu$, where $u_{j k}$ and $v_{k}$ are assumed to have a normal distribution with variance $\sigma_{u}^{2}$ and $\sigma_{v}^{2}$ respectively. Recall from previous sections, we observe three types of word of mouth behaviors: volume of total word of mouth (a combination of positive, mixed and negative word of mouth), volume of positive word of mouth and volume of negative word of mouth. Our research interests are to find out the relationship between total word of mouth and product attributes, positive word of mouth and product attributes, and negative word of mouth and product attributes. Therefore, we construct three proposed models (2) that have same predictor variables and three different dependent variables: $y_{i j k}=$ number of reviews for the model of investigating total word of mouth behavior, $y_{i j k}$ =number of positive reviews for the model of investigating positive word of mouth behavior, and $y_{i j k}$ =number of negative reviews for the model of investigating negative word of mouth behavior. Operationally, we use the following predictor variables and levels:

$$
\text { Model version level }\left(x_{i j k}\right) \text { : }
$$

Reliability rating from Consumer Reports (5=better, 4, 3, 2, 1=worse)

Initial quality rating from J.D. Power \& Associates (5=among the best, 4.5, 4, 3.5, 3, 2.5, 2=the rest)

Performance/Design rating from J.D. Power \& Associates (5=among the best, 4.5, 4, 3.5, 3, 2.5, $2=$ the rest)

Newness (if it is a new designed or redesigned $=1$, otherwise $=0$ )

Product Life Cycle Stage (Standardized)

Price (standardized)

MPG(standardized)

Year of model (they are six categorical variables: 2002 model, 2003 model, 2004 model, 2005 model, 2006 model and 2007 model; reference is 2001 model.)

$$
\text { Brand model level }\left(z_{j k}\right) \text { : }
$$

Body style based on Consumer Reports (they are ten categorical variables: coupe, convertible, luxury, sporty, large, small, pick up, SUV, van and wagon; reference is family.) 


\section{Brand level $\left(y_{k}\right)$ :}

Top brand (if it is top brand $=1$, otherwise $=0$ )

\section{RESULTS}

Table 1 includes descriptive statistics and correlation matrix of the continuous variables in our study. Note that the correlation between reliability and quality is 0.345 .

TABLE 1

DESCRIPTIVE STATISTICS AND CORRELATION MATRIX OF THE CONTINUOUS VARIABLES

\begin{tabular}{|c|c|c|c|c|c|c|c|c|c|c|c|}
\hline & & Mean & Std. Dev & & 2 & 3 & 4 & 5 & 6 & 7 & 8 \\
\hline 1 & Proportion of total wom & 0.00040 & 0.00059 & 1.000 & & & & & & & \\
\hline 2 & Proportion of positive wom & 0.00026 & 0.00041 & 0.951 & 1.000 & & & & & & \\
\hline 3 & Proportion of negative wom & 0.00003 & 0.00006 & 0.501 & 0.341 & 1.000 & & & & & \\
\hline 4 & Reliability & 3.161 & 1.283 & 0.146 & 0.204 & -0.205 & 1.000 & & & & \\
\hline 5 & Quality & 3.402 & 0.925 & 0.002 & 0.070 & -0.200 & 0.345 & 1.000 & & & \\
\hline 6 & Performance/Design & 3.375 & 0.911 & 0.173 & 0.231 & 0.074 & 0.050 & 0.410 & 1.000 & & \\
\hline 7 & Price & 0.000 & 1.000 & 0.066 & 0.098 & 0.099 & -0.115 & 0.282 & 0.647 & 1.000 & \\
\hline 8 & Stage & 0.000 & 1.000 & -0.109 & -0.100 & -0.104 & 0.150 & 0.178 & -0.055 & 0.028 & 1.000 \\
\hline
\end{tabular}

In Table 2, we report the parameter estimates of three models that investigate the volume of total word of mouth, positive word of mouth and negative word of mouth. 
TABLE 2

PARAMETER ESTIMATES FOR THE MODELS OF TOTAL, POSITIVE AND NEGATIVE WORD OF MOUTH

\begin{tabular}{|c|c|c|c|c|c|c|}
\hline & \multicolumn{2}{|c|}{ Total WOM } & \multicolumn{2}{|c|}{ Positive WOM } & \multicolumn{2}{|c|}{ Negative WOM } \\
\hline & Estimate & Std. Err. & Estimate & Std. Err. & Estimate & Std. Err. \\
\hline (Intercept) & $-9.614 * *$ & 0.177 & $-11.080 * *$ & 0.210 & $-10.260 * *$ & 0.350 \\
\hline \multicolumn{7}{|l|}{ Model version level } \\
\hline Reliability & $-0.072 * *$ & 0.013 & 0.001 & 0.017 & $-0.237 * *$ & 0.038 \\
\hline Quality & 0.006 & 0.013 & 0.020 & 0.017 & $-0.101^{*}$ & 0.046 \\
\hline Performance/Design & $0.230 * *$ & 0.024 & $0.305^{* *}$ & 0.031 & -0.017 & 0.070 \\
\hline Newness & $0.301 * *$ & 0.021 & $0.314 * *$ & 0.027 & $0.510^{* *}$ & 0.069 \\
\hline Stage & $-0.267 * *$ & 0.036 & $-0.314 * *$ & 0.043 & $-0.138^{* *}$ & 0.052 \\
\hline Price & -0.042 & 0.042 & -0.074 & 0.052 & 0.100 & 0.078 \\
\hline 2002 Model & $0.225 * *$ & 0.032 & $0.277 * *$ & 0.046 & 0.169 & 0.100 \\
\hline 2003 Model & $0.371 * *$ & 0.033 & $0.508^{* *}$ & 0.047 & 0.127 & 0.104 \\
\hline 2004 Model & $0.474 * *$ & 0.035 & $0.709 * *$ & 0.048 & 0.096 & 0.106 \\
\hline 2005 Model & $0.949 * *$ & 0.038 & $1.311 * *$ & 0.050 & $0.438 * *$ & 0.105 \\
\hline 2006 Model & $0.760 * *$ & 0.042 & $1.147 * *$ & 0.054 & $0.393 * *$ & 0.106 \\
\hline 2007 Model & $0.160 * *$ & 0.049 & $0.523 * *$ & 0.063 & -0.054 & 0.124 \\
\hline \multicolumn{7}{|l|}{ Brand model level } \\
\hline Coupe & 0.135 & 0.252 & 0.255 & 0.303 & 0.186 & 0.419 \\
\hline Convertible & $0.744 * *$ & 0.185 & $1.018^{* *}$ & 0.221 & 0.185 & 0.365 \\
\hline Luxury & $0.392 *$ & 0.152 & $0.479^{* *}$ & 0.181 & $0.490^{*}$ & 0.228 \\
\hline Sporty & $0.414^{*}$ & 0.160 & $0.623^{* *}$ & 0.193 & 0.464 & 0.248 \\
\hline Large & 0.228 & 0.192 & 0.395 & 0.233 & 0.029 & 0.314 \\
\hline Small & 0.119 & 0.143 & 0.079 & 0.174 & 0.156 & 0.202 \\
\hline Pickup & -0.034 & 0.163 & -0.062 & 0.198 & -0.465 & 0.245 \\
\hline SUV & 0.211 & 0.118 & 0.243 & 0.143 & 0.264 & 0.172 \\
\hline Van & $0.317^{*}$ & 0.155 & 0.140 & 0.194 & $0.683^{* *}$ & 0.217 \\
\hline Wagon & $0.545^{*}$ & 0.225 & $0.533^{*}$ & 0.270 & 0.291 & 0.321 \\
\hline \multicolumn{7}{|l|}{ Brand level } \\
\hline Top brand & 0.297 & 0.208 & 0.387 & 0.217 & 0.212 & 0.247 \\
\hline \multicolumn{7}{|l|}{ Random effects } \\
\hline Brand model level & $0.213^{* *}$ & 0.023 & $0.299 * *$ & 0.034 & $0.224 * *$ & 0.045 \\
\hline Brand level & $0.272 * *$ & 0.075 & $0.282 * *$ & 0.083 & $0.346^{* *}$ & 0.108 \\
\hline
\end{tabular}

These predictors include model version level covariates that vary across model versions (reliability, quality, performance/design, newness, stage, price and year of model version), brand model level covariates that vary across brand models (body style), and brand level covariate that only varies across brands (top brand). Our overall goal is to determine the fixed effect of critical product attributes (reliability, quality, performance/design, newness and stage) on the word of mouth behavior and we regard other variables in the models as control variables. 


\section{Reliability/Quality and Performance/Design}

Reliability coefficient is significant and negative $(\beta=-0.072, \mathrm{p}<0.01)$ in the model of total word of mouth, which suggests that failing reliability attribute increases the probability of occurring word of mouth, presumably, negative word of mouth. This assumption is confirmed: reliability has a significantly negative coefficient $(\beta=-0.237, \mathrm{p}<0.01)$ in the model of negative word of mouth, whereas the same coefficient is positive but not significant $(\beta=0.001, \mathrm{p}>0.1)$ in the model of positive word of mouth. Quality has a similar pattern to reliability except that quality is not significant in the model of total word of mouth. Specifically, quality has a significantly negative coefficient $(\beta=-0.101, p<0.05)$ in the model of negative word of mouth, but it is not significant $(\beta=0.02, p>0.1)$ in the model of positive word of mouth. Overall, the findings here suggest that failing reliability or quality significantly increases the probability of occurring negative word of mouth. In contrast, improving reliability or quality has no significant effect on the likelihood of occurring positive word of mouth.

The model for total word of mouth shows that performance/design has a significantly positive $(\beta=$ $0.230, \mathrm{p}<0.01)$ association with the probability of occurring word of mouth. We reason that improving performance/design has a larger impact on positive word of mouth than failing performance/design on negative word of mouth. The magnitude difference results in the overall positive association between performance/design and word of mouth which contains both positive and negative word of mouth. This is again confirmed by the separate analysis of positive and negative word of mouth. Specifically, the positive and significant coefficient of performance/design $(\beta=0.305, p<0.01)$ in the model of positive word of mouth indicates that improving performance/design increases the positive word of mouth tendency. In contrast, the negative and insignificant coefficient of performance/design $(\beta=-0.017, p>0.1)$ in the model of negative word of mouth indicates that failing performance/design does not necessarily leads to the increasing negative word of mouth.

Regarding to the relative impact between reliability/quality and performance/design on the negative word of mouth, a comparison test of the coefficient shows that reliability has a significantly larger impact $\left(\chi_{1}^{2}=7.470, \mathrm{p}<0.01\right)$ on negative word of mouth tendency than performance/design. Quality has a larger coefficient absolute value $(\beta=-0.101)$ than performance/design $(\beta=-0.017)$. However, Quality is not significantly larger than performance/design in the model of negative word of mouth $\left(\chi_{1}^{2}=0.913, p>0.1\right)$. Therefore, the H1 is supported for reliability. With respect to the positive word of mouth, the coefficient of performance/design is significantly larger than the coefficient of reliability $\left(\chi_{1}^{2}=74.257, p<0.001\right)$, as well as the coefficient of quality $\left(\chi_{1}^{2}=57.495, \mathrm{p}<0.001\right)$. This is consistent with our $\mathrm{H} 2$, which posits that improving performance/design has a larger effect on positive word of mouth than improving reliability/quality.

\section{Newness and Stage}

The coefficient of newness is significant and positive across the models of total $(\beta=0.301, p<0.01)$, positive $(\beta=0.314, \mathrm{p}<0.01)$ and negative $(\beta=0.510, \mathrm{p}<0.01)$ word of mouth. This is consistent with $\mathrm{H} 3$, which proposes that newness is positively associated with positive word of mouth tendency as well as negative word of mouth tendency. Since newness is a binary variable ( $1=$ new designed), we can interpret the coefficients of newness as odds ratio. Thus, the odds of generating word of mouth for a new designed product are 1.35 times than odds for a non new designed product. With respect to stage, this coefficient is significant and negative across the three models $(\beta=-0.267, \mathrm{p}<0.01 ; \beta=-0.314, \mathrm{p}<0.01 ; \beta=-0.138, \mathrm{p}<0.01)$, in support of H4. Overall, the implication of this finding is that new designed product drives people talk, either positively or negatively. This capacity of driving word of mouth decreases along with the product life cycle stage. Specifically, a relatively new product that is in the introduction stage is more likely to drive word of mouth than a relatively old product that is in the mature stage.

\section{Additional Analysis of Reliability/Quality and Performance/Design}

Recall that reliability, quality and performance/design are operated as continuous variables in the models of total, positive and negative word of mouth. We next re-estimate two models, one for positive word of mouth and one for negative word of mouth, but including reliability, quality and 
performance/design that are operated as categorical variables. The motivations of this analysis are: 1) getting more meaningful interpretations of coefficients; 2) assuring the results generating from the previous analysis. Table 3 reports the parameter estimates. To conserve space, we only discuss the coefficients of reliability, quality and performance/design. Regarding to positive word of mouth, 5 out of 6 coefficients of performance/design are significant and positive. The magnitudes of coefficients increase in an order $(\beta=0.034<0.268<0.527<0.639<0.677<0.812)$. Therefore, the odds of occurring positive word of mouth for performance/design rating as 3 is 1.3 times than odds for performance/design rating as 2 . The odds ratio increases to 2.25 as comparing performance/design rating as 5 to rating as 2 . Turning to reliability and quality, in line with our expectation, among 10 coefficients, none of them are significant at $5 \%$. Joint coefficient tests show that all reliability coefficients are not different from zero $\left(\chi^{2}=1.39, p>0.1\right)$ and this is also the case for quality coefficients $\left(\chi^{2}=0.361, \mathrm{p}>0.1\right)$. The findings here are consistent with the previous analysis. First, improving performance/design increases the positive word of mouth tendency whereas improving reliability and quality does not necessarily increases the positive word of mouth tendency. Second, improving performance/design has a larger impact on positive word of mouth than improving reliability and quality. 
TABLE 3

PARAMETER ESTIMATES FOR THE MODELS OF POSITIVE AND NEGATIVE WORD OF MOUTH

\begin{tabular}{|c|c|c|c|c|}
\hline \multirow[b]{2}{*}{ Variables } & \multicolumn{2}{|c|}{ Positive WOM } & \multicolumn{2}{|c|}{ Negative WOM } \\
\hline & Estimate & Std. Err. & Estimate & Std. Err. \\
\hline (Intercept) & $-10.460 * *$ & 0.191 & $-10.630 * *$ & 0.261 \\
\hline \multicolumn{5}{|l|}{ Model version level } \\
\hline Reliability-2 & 0.101 & 0.056 & -0.118 & 0.099 \\
\hline Reliability-3 & 0.078 & 0.054 & $-0.520 * *$ & 0.099 \\
\hline Reliability-4 & 0.048 & 0.063 & $-0.560 * *$ & 0.13 \\
\hline Reliability-5 & 0.027 & 0.071 & $-0.978 * *$ & 0.165 \\
\hline Quality-2.5 & 0.03 & 0.048 & -0.175 & 0.103 \\
\hline Quality-3 & -0.059 & 0.046 & $-0.219 *$ & 0.1 \\
\hline Quality-3.5 & 0.036 & 0.05 & $-0.281 *$ & 0.114 \\
\hline Quality-4 & 0.057 & 0.054 & $-0.278 *$ & 0.134 \\
\hline Quality-4.5 & 0.108 & 0.057 & -0.186 & 0.144 \\
\hline Quality-5 & -0.01 & 0.059 & $-0.468 * *$ & 0.159 \\
\hline Performance/Design-2.5 & 0.034 & 0.055 & -0.096 & 0.115 \\
\hline Performance/Design-3 & $0.268 * *$ & 0.059 & 0.021 & 0.122 \\
\hline Performance/Design-3.5 & $0.527 * *$ & 0.065 & -0.122 & 0.139 \\
\hline Performance/Design-4 & $0.639 * *$ & 0.077 & -0.146 & 0.166 \\
\hline Performance/Design-4.5 & $0.677 * *$ & 0.087 & 0.068 & 0.196 \\
\hline Performance/Design-5 & $0.812 * *$ & 0.103 & -0.173 & 0.256 \\
\hline Newness & $0.300 * *$ & 0.028 & $0.499 * *$ & 0.071 \\
\hline Stage & $-0.308 * *$ & 0.043 & $-0.132 *$ & 0.052 \\
\hline Price & -0.075 & 0.052 & 0.122 & 0.081 \\
\hline 2002 Model & $0.277 * *$ & 0.047 & 0.179 & 0.102 \\
\hline 2003 Model & $0.502 * *$ & 0.047 & 0.111 & 0.106 \\
\hline 2004 Model & $0.706 * *$ & 0.048 & 0.074 & 0.107 \\
\hline 2005 Model & $1.322 * *$ & 0.05 & $0.422 * *$ & 0.106 \\
\hline 2006 Model & $1.146 * *$ & 0.055 & $0.360 * *$ & 0.109 \\
\hline 2007 Model & $0.522 * *$ & 0.063 & -0.084 & 0.127 \\
\hline \multicolumn{5}{|l|}{ Brand model level } \\
\hline Coupe & 0.264 & 0.303 & 0.17 & 0.418 \\
\hline Convertible & $1.061 * *$ & 0.222 & 0.226 & 0.366 \\
\hline Luxury & $0.511 * *$ & 0.182 & $0.492 *$ & 0.23 \\
\hline Sporty & $0.631 * *$ & 0.193 & $0.512 *$ & 0.25 \\
\hline Large & 0.379 & 0.233 & 0.005 & 0.312 \\
\hline Small & 0.111 & 0.175 & 0.169 & 0.203 \\
\hline Pickup & -0.038 & 0.198 & $-0.496 *$ & 0.244 \\
\hline SUV & 0.262 & 0.143 & 0.255 & 0.172 \\
\hline Van & 0.197 & 0.195 & $0.657 * *$ & 0.218 \\
\hline Wagon & $0.551 *$ & 0.27 & 0.286 & 0.32 \\
\hline \multicolumn{5}{|l|}{ Brand level } \\
\hline Top brand & 0.395 & 0.218 & 0.205 & 0.245 \\
\hline \multicolumn{5}{|l|}{ Random effects } \\
\hline Brand model level & $0.300 * *$ & 0.034 & $0.221 * *$ & 0.045 \\
\hline Brand level & $0.285 * *$ & 0.084 & $0.335 * *$ & 0.105 \\
\hline
\end{tabular}


With respect to negative word of mouth, we find that 3 out of 4 coefficients of reliability have significant and negative signs. Similarly, 4 out of 6 coefficients of quality have significant and negative signs. The absolute values of reliability coefficients increase from rating as 2 to rating as 5 . In terms of odds ratio, the odds of generating negative word of mouth for reliability rating as 1 are 2.66 times than odds for reliability rating as 5. This odds ratio decreases to 1.13 as comparing to rating as 1 to 2 . Alternatively, the odds of generating negative word of mouth for reliability rating as 2 are 2.35 times odds for rating as 5. Quality coefficients have a similar pattern to reliability coefficients. Turning to the coefficients of performance/design, none of them are significant at $5 \%$. A joint coefficient test also supports that none coefficients of performance/design are significantly different from zero $\left(\chi^{2}=0.292, p>0.1\right)$. Therefore, failing reliability and quality increases the likelihood of occurring negative word of mouth whereas failing performance/design does not. In addition, failing reliability and quality has a larger impact on negative word of mouth than failing performance/design.

\section{Results of Control Variables}

Four control variables (price, year of model, body style and top brand indicator) are included in our models. To conserve the space, we only discuss relevant findings: first, price is not significantly associated with total word of mouth, positive or negative word of mouth. Second, the likelihood of talking about convertible, luxury, sporty, van and wagon is higher than the likelihood of talking about other body styles. Specifically, convertible and sporty are more likely to be talked positively. Conversely, van is more likely to be talked in a negative way. Luxury, however, is more likely to be talked both positively or negatively. Third, top brand has a weaker effect on the positive word of mouth tendency. However, top brand does not help to decrease negative word of mouth tendency.

\section{GENERAL DISCUSSION}

How to provoke, stimulate and produce word of mouth? This is the question that has been explored and studied for decades. Earlier pioneer, such as Dichter (1966) suggests that firms can use advertising, commercial and public relationship to stimulate word of mouth. Godes and Mayzlin (2009) demonstrate that firms can strategically look for a specific segment of customers and recruit them to spread word of mouth. In this article, instead of focusing on this issue from a promotion perspective, we go back to the subject of word of mouth - product, and find evidence that some critical product attributes indeed are associated with word of mouth behavior and designing what types of products partially determines the volume and valence of word of mouth. We therefore believe that our proposed theoretical framework and findings are an important complement to the word of mouth literature and buzz management.

The primary findings and insights this research provides are as follows: reliability/quality, performance/design and innovativeness play qualitatively different roles in generating word of mouth. Specifically, (1) failing reliability/quality stimulates negative word of mouth whereas failing performance/design does not necessarily lead to negative word of mouth. This is because the failure of reliability/quality evokes intensive negative emotions that are high in arousal, and in turn leads to more negative word of mouth. In contrast, the failure of performance/design only evokes minor negative emotions that are low in arousal, and in turn leads to little negative word of mouth; (2) Improving performance/design produces positive word of mouth whereas improving reliability/quality does not necessarily translate to positive word of mouth. This is because the improvement of performance/design evokes intensive positive emotions that are high in arousal, and in turn leads to more positive word of mouth. Conversely, the improvement of reliability/quality evokes minor positive emotions that are low in arousal, and in turn leads to little positive word of mouth; (3) A new (re) designed product drives more both positive and negative word of mouth than a non new product. Similarly, a product with a short history drives more both positive and negative word of mouth than a product with a long history. This is because a newer or relatively newer product is more likely to surprise customers, and surprise is a neural emotion that is high in arousal, and in turn leads to more word of mouth. 


\section{Managerial Implications}

Our central findings that reliability/quality and performance/design play qualitatively different roles in generating word of mouth have substantial implications. In order to maximize word of mouth promotion effect (maximizing positive word of mouth and minimizing negative word of mouth at the same time), companies should improve and maintain both reliability/quality and performance/design at the excellent level. The biggest advantage of this strategy is that companies are able to rely on word of mouth to promote the product, and thus save a huge amount of advertising money. However, companies often face the situation that they have limited resources and have to trade off between selecting reliability/quality or performance/design. Our findings suggest that companies could improve and maintain performance/design at the highest level and maintain reliability/quality at the average (or normal) level. This strategy may help companies still take advantage of positive word of mouth and at the same time keep the negative word of mouth in the acceptable range.

Except for the findings about reliability/quality and performance/design, the finding that a newer product or a relatively newer product is more likely to be talked is worthy to be further discussed. We reason that this is because a newer product or a relatively newer product has more capacity to surprise customer. This capacity of surprising customer declines along with the product life cycle stage. The longer the product has been existed in the market, the more difficult the product surprises customers. This is because the awareness of the product is high and their customers and potential customers develop certain knowledge and expectation about the product. However, the emotion of surprise comes from unexpected experience with the product (e.g. new features or new image). Following this logic, any marketing action that has the potential to lower the surprise level of customers may decrease word of mouth. Companies should be aware of this because companies often rely on such marketing actions, such as repetitive TV commercials, to inform as many consumers as possible. This may not be a good strategy if companies want to take advantage of word of mouth to some degree. The findings of this study suggest that companies should redesign their products (redesigning does not mean a major change of the product and could be the minor improvement of the existed entry.) in a regularly basis. This is particularly important for the product that has been in the market for a long period.

How to design a product that can maximize positive word of mouth effect and minimize negative word of mouth effect at the same time? Our study can provide the solution. To illustrate how our solution works, suppose that an auto maker makes decisions among four automobile attributes: reliability/quality (average v.s. high), performance/design (low v.s. high), new (re)designed model v.s. old version model and convertible v.s. small car. What a design of combinations is able to maximize positive word of mouth effect and at the same time minimize negative word of mouth? On the other hand, what a design may go to the opposite (minimize positive word of mouth and maximize negative word of mouth)? We therefore use the model in Table 2 and calculate the predicted probability of occurring positive and negative word of mouth. Table 4 present the result. Among sixteen possible combinations, two designs outperform the rest of designs in terms of maximizing positive word of mouth and minimizing negative word of mouth: a new (re)designed convertible with both high reliability/quality and performance/design and an old version convertible with both high reliability/quality and performance/design. In contrast, a new (re) designed small car with average reliability/quality and low performance/design may minimize positive word of mouth and maximize negative word of mouth. Recall in the introduction section, we raise the question: is model A that is a new-designed convertible car with high performance and average reliability/quality more likely to drive more positive word of mouth than model B that is a non new-designed small car with a low performance but high reliability/quality? We predict that the chance of driving positive word of mouth is about 9 times higher for model A than for model B. 
TABLE 4

ESTIMATED PROBABILITY AND RANK

\begin{tabular}{|c|c|c|c|c|c|c|c|}
\hline $\begin{array}{l}\text { Reliability/ } \\
\text { Quality }\end{array}$ & $\begin{array}{l}\text { Performance/ } \\
\text { Design }\end{array}$ & $\begin{array}{l}\text { New } \\
\text { (Re)Designed }\end{array}$ & Body Style & $\begin{array}{l}\text { Estimated } \\
\text { Probability of } \\
\text { Producing } \\
\text { Positive WOM }\end{array}$ & $\begin{array}{l}\text { Rank for } \\
\text { Positive } \\
\text { WOM }\end{array}$ & $\begin{array}{l}\text { Estimated } \\
\text { Probability of } \\
\text { Producing } \\
\text { Negative WOM }\end{array}$ & $\begin{array}{l}\text { Rank for } \\
\text { Negative } \\
\text { WOM }\end{array}$ \\
\hline Average & High & Yes & Convertible & 0.00026 & 1 & 0.000020 & 2 \\
\hline Average & High & Yes & Small & 0.00010 & 4 & 0.000019 & 3 \\
\hline Average & High & No & Convertible & 0.00019 & 2 & 0.000012 & 5 \\
\hline Average & High & No & Small & 0.00007 & 6 & 0.000012 & 5 \\
\hline Average & Low & Yes & Convertible & 0.00012 & 3 & 0.000022 & 1 \\
\hline Average & Low & Yes & Small & 0.00005 & 7 & 0.000020 & 2 \\
\hline Average & Low & No & Convertible & 0.00009 & 5 & 0.000013 & 4 \\
\hline Average & Low & No & Small & 0.00003 & 8 & 0.000012 & 5 \\
\hline High & High & Yes & Convertible & 0.00026 & 1 & 0.000010 & 7 \\
\hline High & High & Yes & Small & 0.00010 & 4 & 0.000009 & 8 \\
\hline High & High & No & Convertible & 0.00019 & 2 & 0.000006 & 9 \\
\hline High & High & No & Small & 0.00007 & 6 & 0.000006 & 9 \\
\hline High & Low & Yes & Convertible & 0.00012 & 3 & 0.000011 & 6 \\
\hline High & Low & Yes & Small & 0.00005 & 7 & 0.000010 & 7 \\
\hline High & Low & No & Convertible & 0.00009 & 5 & 0.000006 & 9 \\
\hline High & Low & No & Small & 0.00003 & 8 & 0.000006 & 9 \\
\hline
\end{tabular}

We believe that buzz marketing could benefit from the findings of this study. One unique feature of buzz marketing is that firms initiate it but consumers implement it. Therefore, firms have no complete control of this seemingly 'free' tool. Firms should be careful to select right products in terms of using buzz marketing. For example, if an automobile maker decides to use buzz marketing instead of advertising to promote a car model, the findings here may suggest what type of car models benefit most from buzz marketing while what type of car models are the ones for which the automobile maker should avoid to promote. Clearly, buzz marketing may not a good strategy for a new designed small car with average reliability/quality and poor performance/design because negative word of mouth is more likely to occur. Advertising that positions this small car as a low entry or low price and maintenance cost may be work better for this car. On the other hand, a new designed convertible with both high reliability/quality and performance/design may benefit from buzz marketing because positive word of mouth is more likely to occur.

\section{ENDNOTE}

1. If we do have the car owner level data, the response variable is a binary choice (i.e. post a review or not post a review) that follows a Bernoulli distribution which is actually a special case of Binomial distribution when $\mathrm{n}=1$. 


\section{REFERENCES}

Browne, W.J. (1998). Applying MCMC Methods to Multi-level Models. PhD thesis University of Bath.

Bryk, A.S., \& Raudenbush, S.W. (1992). Hierarchical Linear Models: Applications and Data Analysis Methods. Newbury Park, CA: Sage Publications.

Bucklin, R.E., Siddarth, S., \& Silva-Risso, J.M. (2008) Distribution Intensity and New Car Choice. Journal of Marketing Research, 45(4), 473.

Chernev, A. (2004). Goal-Attribute Compatibility in Consumer Choice. Journal of Consumer Psychology, 14(1,2), 141-150.

Chevalier, J.A., \& Mayzlin, D. (2006). The Effect of Word of Mouth on Sales: Online Book Reviews. Journal of Marketing Research, 43(3), 345-354.

Chitturi, R., Raghunathan, R., \& Mahajan, V. (2007). Form Versus Function:How the Intensities of Specific Emotions Evoked in Functional Versus Hedonic Trade-Offs Mediate Product Preferences. Journal of Marketing Research, 44(4), 702-714.

Chitturi, R., Raghunathan, R., \& Mahajan, V. (2008). Delight by Design: The Role of Hedonic Versus Utilitarian Benefits. Journal of Marketing, 72(3), 48-63.

Cohen, M. A., Eliashberg, J., \& Ho, T-H. (1997). An Anatomy of a Decision-Support System for Developing and Launching Line Extensions. Journal of Marketing Research, 34 (February), 11729.

Day, G.S. (1971). Attitude change, media and word of mouth. Journal of Advertising Research, 11(6), 31-40.

Dellarocas, C. (2006). Strategic Manipulation of Internet Opinion Forums: Implications for Consumers and Firms. Management Science, 52(10), 1577-1593.

Dellarocas, C., \& Narayan, R. (2006). A Statistical Measure of a Population's Propensity to Engage in Post-Purchase Online Word of Mouth. Statistical Science, 21(2), 277-285.

Dellarocas, C.N. (2003). The Digitization of Word-of-Mouth: Promise and Challenges of Online Feedback Mechanisms. Management Science, 49(10), 1407-1424.

Derbaix, C., \& Vanhamme, J. (2003). Inducing word-of-mouth by eliciting surprise - a pilot investigation. Journal of Economic Psychology, 24 (1), February, 99-116.

Dichter, E. (1966). How Word of Mouth Advertising Works. Harvard Business Review, 44, 147-166.

Godes, D., \& Mayzlin, D. (2004). Using Online Conversations to Study Word-of-Mouth Communication. Marketing Science, 23(4), 545 (16 pages).

Godes, D., \& Mayzlin, D. (2009). Firm-Created Word-of-Mouth Communication: Evidence from a Field Test. Marketing Science, 28(4), 721-739.

Godes, D., et al. (2005). The Firm's Management of Social Interactions. Marketing Letters, 6 (3/4), 41528.

Goldstein, H. (2003). Multilevel Statistical Models (Hardcover). Publisher: Wiley; 3 edition.

Greene, W. (2003). Econometric Analysis, 5th ed. Prentice Hall, Upper Saddle River, NJ.

Hoffer, G.E., \& Reilly, R.J. (1984). Automobile Styling as a Shift Variable. Applied Economics, 16 (2), 291-97.

Higgins, E.T. (1997). Beyond pleasure and pain. American Psychologist, 52, 1280-1300.

Hox, J.J. (2002). Multilevel Analysis. Techniques and Applications. Mahwah, NJ: Lawrence Erlbaum Associates.

Katz, E., \& Lazarsfeld, P.F. (1955). Personal Influence; The Part Played by People in the Flow of Mass Communications. Glencoe, Ill. Free Press.

Keller, E. (2007). Unleashing the Power of Word of Mouth: Creating Brand Advocacy to Drive Growth. Journal of Advertising Research, December, 448-452.

Lazarus, R.S. (1991). Emotion and Adaptation. New York: Oxford University Press.

Liu, Y. (2006). Word of Mouth for Movies: Its Dynamics and Impact on Box Office Revenue. Journal of Marketing, 70(July), 74-89.

Mayzlin, D. (2006). Promotional Chat on the Internet. Marketing Science, 25(2),155 (10 pages). 
Mehrabian, A., \& Russell, J. (1974). An Approach to Environmental Psychology. Cambridge, MA: MIT Press.

Mittal, V., Feick. L., \& Murshed, F. (2008). Publish and Prosper: The Financial Impact of Publishing by Marketing Faculty. Marketing Science, 27(3), 430-444.

Oliver, R.L., Rust, R.T., \& Varki, S. (1997). Customer delight: Foundations, findings, and managerial insight. Journal of Retailing, 73(3), 311-326.

Pauwels, K., Silva-Risso, J., Srinivasan, S., \& Hanssens, D.M. (2004). New Products, Sales Promotions, and Firm Value: The Case of the Automobile Industry. Journal of Marketing, 68(4), 142-156.

Ratchford, B., Lee, M-S., \& Talukdar, D. (2003). The Impact of The Internet on Information Search for Automobiles. Journal of Marketing Research, 40(2), 193-209.

Roseman, I.J. (1991). Appraisal Determinants of Discrete Emotions. Cognition and Emotion, 5(3), 161200.

Rust, R.T., \& Oliver, R.L. (2000). Should We Delight the Customer? Academy of Marketing Science Journal, 28(1), 86-94.

Sherman, R., \& Hoffer, G. (1971). Does Automobile Style Change Pay Off? Applied Economics, 3(3), 153-65.

Srinivasan, S., Pauwels, K., Silva-Risso, J., \& Hanssens, D.M. (2009). Product Innovations, Advertising, and Stock Returns. Journal of Marketing, 73(1), 24-43.

Venkatesan, R., Mehta, K., \& Bapna, R. (2007). Do Market Characteristics Impact the Relationship Between Retailer Characteristics and Online Prices? Journal of Retailing, 83(3), 309.

Westbrook, R.A. (1987). Product/Consumption-Based Affective Responses and Post-purchase Processes. Journal of Marketing Research, 24(3), 258-270.

Westbrook, R.A., \& Oliver, R.L. (1991). The Dimensionality of Consumption Emotion Patterns and Consumer Satisfaction. Journal of Consumer Research, 18(1), 84-91. 